\title{
FORMATION OF JUDO TECHNIQUE, USING OF THE BASE OF TECHNICAL PREPARATION OF WRESTLERS OF NATIONAL WRESTLING “KAZAKH KURES”.
}

\author{
Y. Nasiyev ${ }^{1}$, M. Shepetyuk ${ }^{2}$, B. Konakbayev ${ }^{2}$, B.Dzhamberbayev ${ }^{2}$ \\ ${ }^{1}$ National sports academy of Vassil Levski, Bulgaria, Sofia, \\ ${ }^{2}$ Kazakh academy of sport and tourism. Republic of Kazakhstan
}

\begin{abstract}
Annotation. The exit of the wrestlers of Kazakh kures (the most popular kind of wrestling in Kazakhstan) on the international tournaments on others kinds of wrestling, first of all judo, to participate in the Olympic Games, required the careful analysis of their technical preparation that to correspond to the rules of other kinds of wrestling during the competitions.

During the researches of technical preparation of participants of the Championships of the Republic of Kazakhstan on wrestling of Kazakh kures and judo, by authors were defined the technical methods used at official competitions in these kinds of wrestling.

Relying on the received results of research, the most effective technical activities applied by the leading wrestlers in the competitions on Kazakh kures and judo revealed. The practical recommendations of improvement of basic technique of wrestling of Kazakh kures for its effective application in judo competitions were developed.
\end{abstract}

Keywords: Kazakh kures, judo, technical preparation, effectiveness of receptions.

Introduction. In recent years Kazakhstan gives much attention to development of national sports, the most popular of which is a wrestling of Kazakh kures. On the wrestling of Kazakh kures hold the World Cup, the championship of Asia and Europe, the command tournament "Eurasia Barysi" and series of the international competitions. The most popular tournament on the wrestling of Kazakh kures is an Absolute Championship of the Republic of Kazakhstan, which is held annually, where to the winner, give the most prestigious title "Kazakhstan Barysi”.

Participation of wrestlers of Kazakh kures on the international tournaments on the others kinds of wrestling, first of all on judo, with the purpose to participate in the Olympic Games, required the necessity to conduct the researches of the analysis of technical preparation of wrestlers of Kazakh kures and judo, to define the technical methods used at official competitions in these two kinds of wrestling. It requires new approaches to organization of the formation of arsenal of technical activities of the wrestlers Kazakh kures for their effective application in Judo on competitions of various levels.
Methodology. For the solution of the put problem the following research tasks have been defined:

to objectively estimate variety and quality of the technical activities applied in competitions on the Kazakh kures and judo; to carry out the comparative analysis of technical preparation of participants of competitions in judo and the Kazakh kures; to develop the recommendations of planning and improvement of technical preparation of wrestlers Kazakh kures, for successful performance in judo competitions.

Methods are used: analysis of scientific and methodical publications; pedagogical observations, videos of competitive meetings; registration of technical activities, methods of mathematical statistics.

Results. For determination of technical preparedness of participants of competitions on the Kazakh kures, were made the observations in the World Cup (Almaty, 2006), in the Championship of the Republic of Kazakhstan (RK) - Karaganda, 2016, in Rural games (Kyzylorda, 2015) with the help of video and shorthand registration of fights. Results are presented in table 1 . 
Table 1 - The technical-tactical activities, estimated by judges on official tournaments on Kazakh kures

\begin{tabular}{|c|c|c|c|c|c|c|c|c|c|c|c|c|c|}
\hline \multirow[t]{3}{*}{ Techniques, throws } & \multicolumn{12}{|c|}{ Estimates of technical activities in competitions } & \multirow{3}{*}{ 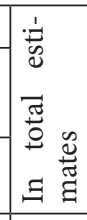 } \\
\hline & \multicolumn{4}{|c|}{ World Cup, 2006} & \multicolumn{4}{|c|}{$\begin{array}{l}\text { Championship RK, } \\
2016\end{array}$} & \multicolumn{4}{|c|}{ Rural games, 2015} & \\
\hline & $\mathrm{T}$ & $\begin{array}{l}\mathrm{Zh} \\
\mathrm{zh}\end{array}$ & $\mathrm{Zh}$ & B & $\mathrm{T}$ & $\begin{array}{l}\mathrm{Zh} \\
\mathrm{zh}\end{array}$ & $\mathrm{Zh}$ & B & $\mathrm{T}$ & $\begin{array}{l}\mathrm{Zh} \\
\mathrm{zh}\end{array}$ & $\mathrm{Zh}$ & B & \\
\hline floating hip (koshiwaza) & 11 & 4 & 4 & 9 & 9 & 14 & 2 & 18 & 3 & 4 & 2 & 11 & 91 \\
\hline forward leg trip (tai-otoshi) & 4 & 4 & 3 & 2 & 4 & 5 & 6 & 19 & 3 & 10 & 6 & 24 & 90 \\
\hline outside leg trip (o-soto-otoshi) & 4 & 5 & 1 & 4 & 15 & 12 & 10 & 13 & 13 & 11 & 11 & 11 & 110 \\
\hline corner throw (sumigaeshi) & 2 & 5 & 1 & 1 & 1 & 9 & 12 & 6 & 6 & 8 & 5 & 12 & 68 \\
\hline ankle trip & 1 & 4 & 7 & 14 & 2 & 8 & 10 & 25 & 2 & 6 & 11 & 29 & 119 \\
\hline by reaping foot & & 1 & & & 1 & 2 & 2 & 3 & 2 & & & 4 & 15 \\
\hline by reaping hip & 5 & 2 & 7 & 4 & 6 & 5 & 12 & 10 & 5 & 8 & 10 & 6 & 80 \\
\hline buttock, hip-roll (se oi-nage) & & 3 & & 1 & 1 & 13 & 7 & 6 & 4 & 12 & 2 & 6 & 55 \\
\hline by pick-up (harai-goshi) & 14 & 9 & 3 & 6 & 12 & 20 & 8 & 12 & 10 & 13 & 5 & 13 & 125 \\
\hline drop back & 4 & 1 & 2 & 4 & 7 & 10 & 12 & 6 & 9 & 10 & 5 & 7 & 77 \\
\hline breaking of balance (tsukuri) & 13 & 6 & 9 & 49 & 15 & 24 & 12 & 80 & 5 & 9 & 9 & 46 & 277 \\
\hline by encirclement & 1 & 1 & 1 & 2 & & 3 & 2 & 1 & 2 & 10 & 4 & 3 & 30 \\
\hline Total & 59 & 45 & 38 & 96 & 73 & 125 & 95 & 199 & 64 & 1011 & 70 & 172 & 1137 \\
\hline
\end{tabular}

Note: T-assessment «taza zhenis», Zhzh - assessment «zharty-zhenis», Zh- assessment « zhambas », B- assessment « bouck ».

The analysis of the obtained data shows that at these competitions of the referees most often assessed the throws: leg trips (249 times), ankle trips (136 times), reaping's (111 times), pick-ups (145 times) and breaking of balance (273 times). The wrestlers have gained the greatest number of clean victories by performing throws: leg trips (43 times), reaping's (19), breaking of balance (33), pick-ups (36), floating hip (23), drop back (16). Were revealed differences between the estimated receptions in young men and adults.

In the first World Cup on the Kazakh kures have taken part the athletes from 45 states of various continents. Registration of technical-tactical activities was carried out on the E.M. Chumakov's method. 234 receptions at 91 registered meeting have been estimated.

Throws were the most popular technical activities of participants: breaking of balance which were productively applied 77 times, pick-ups - 32 times, throws floating hip - 28 times, throws by ankle trips - 26 times, outside leg trip - 14 times, forward leg trip - 13.

On the quality, the estimated technical-tactical activities distributed as follows:
Taza (clear victory) it is awarded by referee of 59 times. Of them for throws: pick-ups - 14 times; breaking of balance - 13 times; floating hip - 11 times; reaping hip - 5 times; outside and forward leg trip and drop back on 4 times; by corner throw - 2 times; for ankle trips and encirclement on 1 time. Such throws as reaping foot, buttock have not been estimated on "taza" during all tournament.

Zharty-zhenis (half victory) was awarded by referee of 45 times, of them for throws: pick-ups - 9 times; breaking of balance - 6 times; outside leg trip and corner throw on 5 times; floating hip, forward leg trip and ankle trip on 4 times; buttock - 3 times; reaping hip - 2 times; by reaping foot, drop back and encirclement on 1 time.

The mark "zhambas" was awarded by referee of 38 times for throws: breaking of balance -9 times, ankle trip and reaping hip on 7 times, floating hip 4 times, forward leg trip and pick-ups on 3 times, drop back 2 times, outside leg trip, corner throw and encirclement -1 time.

Bouck (the minimum assessment) was awarded by referee of 96 times, from them for throws: breaking of balance - 49 times; ankle trip - 14 times; floating hip - 9 times; pick-ups of 6 times; outside leg trip, 
drop back and reaping hip on 4 times; encirclement and forward leg trip 2 times; corner throw and buttock on 1 time.

Evaluating the quality of the receptions, it can be noted that the composition of the participants in the World Cup was not equivalent. From 91 registered meetings, 59 have ended taza (clear victories).

Teams from 14 regions and cities of Astana and Almaty took part in the championship of Kazakhstan and Rural Games. Technical-tactical activities at 269 meetings took down in shorthand, where referees (Table 1) assessed 897 activities. At these meetings of the referees estimated throws: breaking of balance - 200 times; outside leg trip - 96 times; ankle trip - 93 times; pick-ups - 93 times; floating hip - 63 times; drop back - 66 times; forward leg trip 77 times; reaping hip - 62 times; corner throw - 59 times; buttock - 51 times; reaping foot -14 times.

On the quality, the estimated technical-tactical activities distributed as follows:

Taza - 137 estimates, of them for throws: breaking of balance -20; outside leg trip - 28; pick-ups - 22; floating hip - 12; drop back - 16; reaping hip -11 ; forward leg trip -7 ; ankle trip -4 ; corner throw 7 ; buttock -5 .

Zharty-zhenis - 226 estimates, of them for throws: breaking of balance -20 , pick-ups - 22, outside leg trip -28 , floating hip -12 , buttock -5 , drop back - 16, ankle trip - 4, corner throw -7 , forward leg trip -7 , reaping hip -11 , reaping foot -3 , encirclement -2 .

Zhambas - 165 estimates, of them for throws: breaking of balance -21 ; drop back - 17; corner throw -17 ; reaping hip - 22 times; outside leg trip -21 ; ankle trip - 21; buttock - 9; pick-ups - 13; forward leg trip -12 ; floating hip -4 ; reaping foot -2 ; encirclement -5 .

Bouck - 371 estimates, of them for throws: breaking of balance -126; ankle trip - 54; forward leg trip 43; floating hip - 29; pick-ups - 25; outside leg trip -24 ; reaping hip - 16; corner throw -18 ; drop back
- 13; reaping foot -7 ; buttock -12 ; encirclement -4 .

The most popular throw is a breaking of balance, which was estimated 200 times, cannot be attributed to qualitative, 126 times it was estimated by the minimum estimate of "bouck", which is $63 \%$ of the total number of evaluations.

Estimating technical preparation of participants of the three above listed competitions, it should be noted that were most often estimated by referees such throws as breaking of balance, pick-ups, floating hip and outside leg trip. Throws by a reaping foot, by encirclement and buttock were rarely estimated. The most effective estimates were put by referee for throws by pickup, outside leg trip and buttock. 260 men took part in the competitions, including all the strongest judokas of Kazakhstan. In total, the referees evaluated 364 technical activities at the men throw from a standing position and throw from a ground position. The distribution of the number of receptions estimated by the referees throw from a standing position on weight categories is reflected in table 2 .

The greatest number of times the referees estimated the throws buttock from knees of 65 times, 17 times this reception has been estimated in weight category up to $66 \mathrm{~kg}$, on 11 times in weight categories up to 60 $\mathrm{kg}$ and $81 \mathrm{~kg}$ and 9 times in weight category up to 90 $\mathrm{kg}$. On the second place on the quantity of estimates the throw breaking of balance of 39 times, but it was more often used as counters in weight categories up to $73 \mathrm{~kg}$ (9 times), $60 \mathrm{~kg}$ and $66 \mathrm{~kg}$ (on 7 times). On 31 times by referees have estimated throws by ankle trip and by pick-ups under one leg. Throws by ankle trip more often were applied in weight categories up to $73 \mathrm{~kg}$ (10 times), up to $90 \mathrm{~kg}$ ( 6 times) up to $66 \mathrm{~kg}$ (5 times). Throws by pick-ups under one leg more often were estimated in weight categories up to 60 $\mathrm{kg}$ (7 times), over $100 \mathrm{~kg}$ (6 times), up to $66 \mathrm{~kg}, 73 \mathrm{~kg}$ and $81 \mathrm{~kg}$ on (5 times). On 28 times throws outside leg trip and by corner throw were effective. The outside leg trip was estimated in weight categories up to $81 \mathrm{~kg}$ (8 times), up to $60 \mathrm{~kg}$ and $90 \mathrm{~kg}$ (on 5 times). Throws by corner were most effective at athletes of weight categories to $66 \mathrm{~kg}$ and over $100 \mathrm{~kg}$ (on 6 times), up to $100 \mathrm{~kg}$ (5 times). 
Table 2 - Number of the estimated technical activities on weight categories at the men

\begin{tabular}{|l|l|l|l|l|l|l|l|l|l|}
\hline \multirow{2}{*}{} & № & Technical action (throw) & \multicolumn{3}{l}{ Weight category } & \multirow{2}{*}{ Total } \\
\cline { 3 - 10 } & & 60 & 66 & 73 & 81 & 90 & 100 & +100 & \\
\hline 1 & floating hip & 4 & 6 & 4 & 1 & 4 & 1 & 1 & 21 \\
\hline 2 & buttock & - & - & - & 1 & 1 & - & - & 2 \\
\hline 3 & buttock from knees & 11 & 17 & 4 & 11 & 9 & 7 & 6 & 65 \\
\hline 4 & forward leg trip & 2 & 2 & 1 & 2 & - & - & - & 7 \\
\hline 5 & outside leg trip & - & 5 & 4 & 8 & 5 & 3 & 3 & 28 \\
\hline 6 & ankle trip & 3 & 5 & 10 & 4 & 6 & 2 & 1 & 31 \\
\hline 7 & reaping foot & - & - & 1 & 1 & - & - & - & 2 \\
\hline 8 & reaping hip & 8 & 6 & 4 & 2 & 2 & 2 & - & 24 \\
\hline 9 & pick-up under one leg & 7 & 5 & 5 & 5 & 1 & 2 & 6 & 31 \\
\hline 10 & pick-up under two legs & - & 2 & 1 & 1 & - & 4 & 2 & 10 \\
\hline 11 & drop back & 1 & - & - & 1 & 1 & - & 1 & 4 \\
\hline 12 & flying near with emphasis foot & 2 & 1 & - & 1 & - & - & - & 4 \\
\hline 13 & flying near with emphasis hip & 5 & 1 & 3 & - & 1 & 2 & 1 & 13 \\
\hline 14 & breaking of balance & 7 & 7 & 9 & 5 & 5 & 3 & 3 & 39 \\
\hline 15 & corner throw & 3 & 6 & 2 & 3 & 3 & 5 & 6 & 28 \\
\hline Total & & 53 & 63 & 48 & 46 & 38 & 31 & 36 & 309 \\
\hline
\end{tabular}

24 times estimated throws by reaping hip, the most often in weight categories to $60 \mathrm{~kg}$ ( 8 times), up to $66 \mathrm{~kg}$ ( 6 times), up to $73 \mathrm{~kg}$ ( 4 times). 21 times by referees were estimated the throws floating hip: in weight category up to $66 \mathrm{~kg}$ ( 6 times), in weight categories up to $60 \mathrm{~kg}, 73 \mathrm{~kg}$ and $90 \mathrm{~kg}$ (on 4 times). From a standing position seldom were applied such effective throws as: buttock throw from a standing position ( 2 times); forward leg trip (7 times); by reaping foot ( 2 times); drop back and stomach throw (on 4 times). The throw of flying near with emphasis hip estimated 13 times, that allows us to speak about return of this technical action.

Analyzing the technical actions estimated by the referees from a standing position, it is possible to say that participants began to hold more receptions, protection against which is less effective: throws buttock from knees, ankle trips and pick-ups. To such less dangerous receptions, it is necessary to carry and breaking of balance, which was often used as counters from the attacks of opponent. Athletes are fighting more circumspectly, eliminating from their arsenal any activities, in the reliability of which they doubt. In 42 meetings out of 265 , referees did not assess not a one technical action that is almost $16 \%$ of the fights. Such tactics of conducting competitive struggle is less dangerous, but its frequent use reduces the spectacle of judo, reduces the number of attacking actions and attraction for spectators. But most importantly, at the athletes lose confidence in the effectiveness of their activities, that often manifests itself at the participation in international starts with more prepared fighters.

In the wrestling ground-work athletes conducted 55 evaluated actions, from which: 40 were received for hold-down (osaekomiwaza), 10 for painful receptions and 5 for necklocks (shimewaza). To obtain comprehensive and objective information, we analyzed the quality of the evaluated technical activities (Table 3). The number of estimates ippon 73 , waza-ari - 125, yuko - 111.

Carrying out the comparative analysis of technical preparedness of participants of the Championship of the Republic of Kazakhstan with the competitions of 2014 and 2015 it should be noted that the number of qualitative estimates has increased: the waza-ari is $40 \%$, and ippon $29 \%$, the estimates of the yuko are $31 \%$. Practically $69 \%$ of the estimates were waza-ari and ippon, although earlier their number was slightly more than $50 \%$. It can be said that in the course of improving the technique of judo, coaches paid more attention to the quality of the performance of technical activities. 
Table 3 - Indicators of technical preparedness of wrestlers of Kazakh kures and judo

\begin{tabular}{|c|c|c|c|c|c|c|c|c|c|}
\hline \multirow[t]{3}{*}{ Throw } & \multicolumn{5}{|l|}{ Kazakh kures } & \multicolumn{4}{|l|}{ Judo } \\
\hline & \multirow{2}{*}{\begin{tabular}{|l|} 
number of re- \\
ceptions and $\%$
\end{tabular}} & \multicolumn{4}{|c|}{ quantity of estimates } & \multirow{2}{*}{$\begin{array}{l}\text { number of recep- } \\
\text { tions and } \%\end{array}$} & \multicolumn{3}{|c|}{ quantity of estimates } \\
\hline & & $\mathrm{T}$ & Zhzh & $\mathrm{Zh}$ & $\mathrm{B}$ & & ippon & waza-ari & yuko \\
\hline \begin{tabular}{|l|} 
1. floating hip \\
\end{tabular} & $93-7,9 \%$ & 23 & 22 & 10 & 38 & $21-2 \%$ & 6 & 6 & 9 \\
\hline \begin{tabular}{|l|} 
2. forward leg trip \\
\end{tabular} & $90-7,7 \%$ & 11 & 19 & 15 & 45 & $7-2,4 \%$ & 1 & 3 & 3 \\
\hline 3. outside leg trip & $110-9,5 \%$ & 32 & 28 & 22 & 28 & $28-9,6 \%$ & 12 & 12 & 4 \\
\hline 4. ankle trip & $119-10,2 \%$ & 5 & 18 & 28 & 68 & $31-10,6 \%$ & 6 & 12 & 13 \\
\hline 5. reaping foot & $115-1,3 \%$ & 3 & 3 & 2 & 7 & $2-0,7 \%$ & - & 2 & - \\
\hline 6. reaping hip & $80-6,9 \%$ & 16 & 15 & 29 & 20 & $24-8,2 \%$ & 5 & 11 & 8 \\
\hline 7. buttock & $55-4,7 \%$ & 5 & 28 & 9 & 13 & $2-0,7 \%$ & 1 & - & 1 \\
\hline 8. pick-up & $125-10,7 \%$ & 36 & 42 & 16 & 31 & $41-14 \%$ & 9 & 23 & 9 \\
\hline 9. drop back & $77-6,6 \%$ & 20 & 21 & 19 & 17 & $4-1,4 \%$ & - & 1 & 3 \\
\hline 10. encirclement & $53-4,6 \%$ & 3 & 14 & 30 & 6 & - & - & - & - \\
\hline 11. breaking of balance (tsukuri) & $278-23,9 \%$ & 33 & 39 & 30 & 176 & $39-13,4 \%$ & 7 & 14 & 18 \\
\hline 12. corner throw (sumigaeshi) & $68-5,8 \%$ & 9 & 22 & 18 & 19 & $28-9,6 \%$ & 11 & 6 & 11 \\
\hline 13. buttock from knees & - & - & - & - & - & $65-22,3 \%$ & 11 & 27 & 27 \\
\hline Total & 1163 & 196 & 271 & 228 & 468 & 292 & 69 & 117 & 106 \\
\hline
\end{tabular}

The greatest number of estimates ippon judokas have received for throws in a standing position: corner throws and throws buttock from knees (11), outside leg trip (12), inner thigh (uchimata) (9). The mark of waza-ari awarded for throws: 16 times by pickup; 14 times by breaking of balance; 12 times for throws outside leg trip and by ankle trip; 11 times for throws reaping hip. The yuko referees awarded 27 times for throw buttock from knees, 18 times for breaking of balance, 13 times for throws by ankle trip, 9 times for throws floating hip and 8 times for reaping hip, 11 times for corner throw.

Summarizing the results of technical preparedness of the participants of the competitions on Kazakh kures and judo, we conducted a competitive analysis of the evaluated activities (Figure 1).

In wrestling the Kazakh kures of the referees have put down 1163 marks, more often were assessed the following techniques: breaking of balance of 278 times $(23,9 \%)$, throws by pick-up of 125 times $(10,7 \%)$, throws by ankle trip of 119 times $(10,2 \%)$, throws by outside leg trip of 110 times $(9,5 \%)$, throws by forward leg trip of 90 times $(7,7 \%)$, throws by floating hip 93 times (7,9\%), throws by reaping hip of 80 times $(6,9 \%)$, throws by drop back of 77 times $(6,6 \%)$, corner throw of 68 times $(5,8 \%)$, buttock of 55 times $(4,7 \%)$, by encirclement 53 times $(4,6 \%)$, throws by reaping foot of 15 times $(1,3 \%)$.

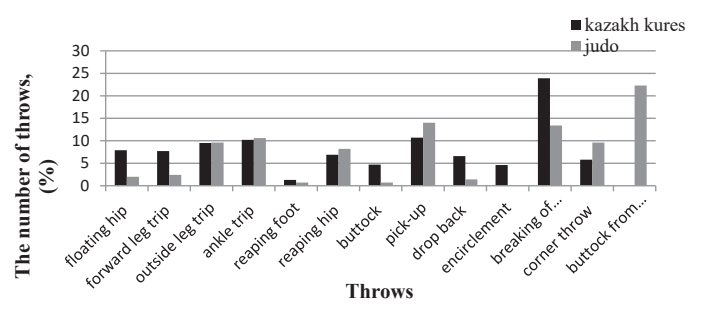

Figure 1 - Indicators of technical preparedness of wrestlers of Kazakh kures and judo

In wrestling of judo of the referees have estimated 292 activities from them: for throw buttock from knees 65 times (22,3\%), throw by pick-up have estimated 41 times (14\%), breaking of balance 39 times $(13,4 \%)$, throws by ankle trip of 31 times $(10,6 \%)$, throws by outside leg trip and corner throw on 28 times $(9,6 \%)$, throws by reaping hip 24 times $(8,2 \%)$, throws by floating hip of 21 times $(7,2 \%)$, throws by forward leg trip of 7 times $(2,4 \%)$, throws by drop back 4 times $(1,4 \%)$, buttock and reaping foot on 21 times $(0,7 \%)$.

\section{Conclusions and practical recommendations.}

The most effective in both kind of wrestling were: breaking of balance of $23.9 \%$ - Kazakh kures and $13,4 \%$ - judo; throws by pick-up $10,7 \%$ and $14 \%$; throws by ankle trip 10,2\% and 10,6\%; throws by outside leg trip $9,5 \%$ and $9,6 \%$; throws by floating hip $7,9 \%$ and $7,2 \%$. 
On the quality of the evaluated activities in Kazakh kures on the leading positions: throw by pick-up of 36 clear victories; 42 zharty-zhenis (half victory); breaking of balance 33 and 39; throws by outside leg trip 32 and 28; throws by floating hip 23 and 22; throws by drop back 20 and 21; throws by reaping hip 16 and 15.

In wrestling of judo, the most quality estimates are received from referees for throws: outside leg trip 12 ippon, 12 waza-ari (half victory); throws buttock from knees 11 and 27; corner throw 11 and 6; throws by ankle trip 6 and 12; throws by floating hip 6 and 6; breaking of balance 7 and 14; throws by reaping hip 5 and 11 .

It is revealed, that in wrestling of Kazakh kures and wrestling of judo, effective receptions coincide overall. To such receptions, it is necessary to carry the throws by pick-up, breaking of balance, throws by ankle trip, throws by outside leg trip and throws by reaping foot. Only two effective receptions as encirclement in Kazakh kures (4.6\%) and throws buttock from knees in judo (22.8\%) can be applied only in their kinds.

It is determined that on the quality of technical activities, the leading receptions also practically coincide. These include throws: breaking of balance, throws by pick-up, throws by outside leg trip, throws by ankle trip, throws by reaping hip, and throws by floating hip.

For the successful performance of the wrestlers of Kazakh kures in judo, it is recommended:

In training process are to pay more attention, on the improvement of technical activities, which are successfully applied in Kazakh kures and judo.
These include throws: breaking of balance, throws by pick-up, throws by outside leg trip, throws by ankle trip and throws by floating hip;

Improvement of receptions effective in judo should be carried out only after getting of the base techniques of Kazakh kures; when choosing of the individual technique of athletes, it is necessary, to take into account the morpho-functional features of their organism; the application of technical activities of Kazakh kures in judo competitions will be effective, if the structure of the reception is kept in accordance with the rules of the competition.

\section{Literature}

Shepetyuk M.N., Almukhanbetova G.N., Ten A. V., Nasiyev Y. K., Dzhamberbayev B. A. Control to the technical preparedness of the participants of the championship of the Republic of Kazakhstan on judo // Theory and Methods of Physical Culture.- 2017.-No. 1.- P. 86-92.

Shepetyuk M.N., Andruchsishin, Y.P., Shepetyuk N.M. Analysis of technical-tactical preparation of judokas // Theory and methodology of physical culture.-2016.- No. 1.- P. 188-193.

Shepetyuk M.N., Baishulakov Zh.S., Nauryzbekova S.M. Technical-tactical preparation of the participants in the Spartakiad of students of the youth of the Republic of Kazakhstan on Kazakh kures // Theory and Methods of Physical Culture.-2006.- № 2.- P. 126-131. Shepetyuk M. N., Baishulakov Zh.S., Improvement of the training process on Kazakh kures // Tashkent, 2006, International scientific-practical conference "Problems of improving the preparation system" of highly qualified athletes to the Olympic Games ".- P. 84-87.

Shepetyuk M.N., Krushbekov E. B., Ten A. V., Almukhanbetova G. N. Evaluation of the technical preparedness of judokas in the conditions of competitions // Theory and Methods of Physical Culture, № 2, 2016.P. 63-67.

Svishchev I.D. Analysis of the technical-tactical activities of the world's strongest judokas in competitive activity // Sports Wrestling: Yearbook.- M.: F\&S, 1981.- P. 11-13. 